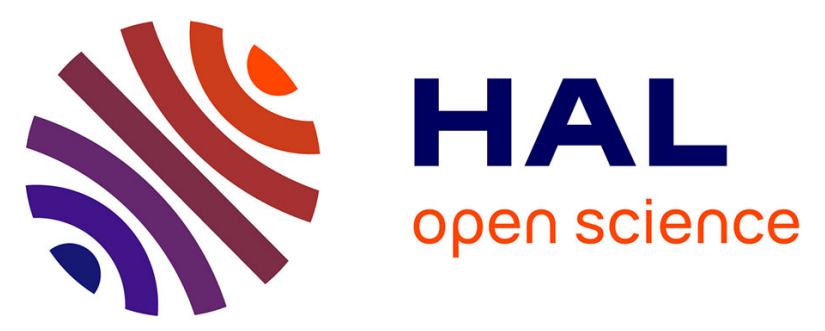

\title{
Diffusion and Electrical Activation After a Rapid Thermal Annealing of an As and B-Co-Implanted Polysilicon Layer
}

\author{
C. Gontrand, P. Sellitto, S. Tabikh, S. Latreche, A. Kaminski
}

\section{- To cite this version:}

C. Gontrand, P. Sellitto, S. Tabikh, S. Latreche, A. Kaminski. Diffusion and Electrical Activation After a Rapid Thermal Annealing of an As and B-Co-Implanted Polysilicon Layer. Journal de Physique III, 1997, 7 (1), pp.47-58. 10.1051/jp3:1997109 . jpa-00249572

\section{HAL Id: jpa-00249572 https://hal.science/jpa-00249572}

Submitted on 1 Jan 1997

HAL is a multi-disciplinary open access archive for the deposit and dissemination of scientific research documents, whether they are published or not. The documents may come from teaching and research institutions in France or abroad, or from public or private research centers.
L'archive ouverte pluridisciplinaire HAL, est destinée au dépôt et à la diffusion de documents scientifiques de niveau recherche, publiés ou non, émanant des établissements d'enseignement et de recherche français ou étrangers, des laboratoires publics ou privés. 


\title{
Diffusion and Electrical Activation After a Rapid Thermal Annealing of an As and B-Co-Implanted Polysilicon Layer
}

\author{
C. Gontrand $\left(\left(^{1,2, *}\right)\right.$, P. Sellitto $\left({ }^{3}\right)$, S. Tabikh $\left({ }^{4}\right)$, S. Latreche $\left({ }^{1}\right)$ and
}

A. Kaminski $\left({ }^{1}\right)$

( ${ }^{1}$ Laboratoire de Physique de la Matière, Institut National des Sciences Appliquées de Lyon, 20 avenue A. Einstein, 69621 Villeurbanne Cedex, France

$\left({ }^{2}\right)$ CIMIRLY (Centre Interuniversitaire de Microélectronıque de la Région Lyonnaise),

20 avenue A. Einstein, 69621 Villeurbanne Cedex, France

$\left({ }^{3}\right)$ Groupe d'Études des sem1-conducteurs, Université des Sciences et Technıques du Languedoc, 34095 Montpellier Cedex, France

$\left({ }^{4}\right)$ Université des Antilles et de la Guyane, boulevard Légitimus, BP 771,

97173 Pounte-à-Pitre Cedex, France

(Received 9 April 1996, revised 12 September 1996, accepted 3 October 1996)

PACS.61 $72-y$ - Defects and impurities in crystals

PACS.66.30.-h - Diffusion in solids

\begin{abstract}
This work provides an experimental insight into the physical mechanısms involved in the co-diffusion of arsenıc and boron in polysilicon/monocrystalline $\mathrm{S}$ i bilayers, during the formation of shallow $\mathrm{N}^{+}$emitters for the BiCMOS technology The RTA-induced redistribution of As and B successively implanted in a $380 \mathrm{~nm}$ LPCVD polysilicon layer is studied by SIMS measurements. Hall effect, as well as sheet resistance measurements, show that the electrical activation of dopants in the co-implanted structures is satisfactory from a RTA temperature of $1100^{\circ} \mathrm{C}$.
\end{abstract}

Résumé. - Nous présentons ıci un travail expérımental mettant en évidence les mécanısmes physiques intervenant dans la co-diffusion de l'arsenic et du bore dans une bicouche polysilicium sur silıcium polycrystallın, durant la formatıon des émetteurs étroıts $\mathrm{N}^{+}$destınés à la technologie BiCMOS La redıstribution de As et B induite par un RTA, successivement implantés dans une couche de polysilıcium de $380 \mathrm{~nm}$, est appréhendée par des mesures SIMS. Des mesures par effet Hall et par résistances par carrés mettent en évidence que l'actıvité électrıque des dopants dans les structures implantées est satisfaisante à partır d'une température de $1100^{\circ} \mathrm{C}$.

\section{Introduction}

Highly doped polysilicon is now currently employed in Integrated Circuit technologies, either as a gate material on CMOS devices, or for the self-aligned contacts and active emitters of bipolar transistors. In this latter case, an implanted polysilicon top layer is used as a dopant source for the underlying monocrystalline emitter region, according to the following sequence

(*) Author for correspondence (e-mall gontrand@cegely.insa-lyon.fr). 
of operations: a Low Pressure Chemical Vapor Deposited (LPCVD) polysilicon layer is first deposited on top of the monocrystalline substrate after appropriate chemical cleaning. Afterwards a high dose of As is implanted with a peak concentration in the polysilicon. Annealing of the structure is finally performed at elevated temperature in order to produce the electrical activation of the As ions, and their rapid redistribution within the polycrystalline layer and across the interface into the monocrystalline substrate [1]. Shallow and highly doped emitters can be formed this way using Rapid Thermal Annealing (RTA), because of the beneficial effect of high temperatures and low dwell times for minimizing dopant diffusion [2]. In this framework, CMOS compatible bipolar transistor technologies (BiCMOS) are developed, in which the gate As-doped polysilicon layer is used as a dopant source for the emitter of the bipolar transistor [3]. However, the base contacts of the bipolar transistor located at the drain/source region of the MOS geometry necessitate a B implantation at medium dose (extrinsic base), which is also received by the polysilicon layer. Annealing therefore causes the rapid and simultaneous redistribution of $\mathrm{B}$ and $\mathrm{As}$ in and from the polysilicon layer during the $\mathrm{N}^{+}$emitter drive-in. The problem of dopant co-diffusion is then crucial $[4,5]$. In order to achieve a good control of the emitter doping profile, the diffusion behaviour of both As and B during RTA must be experimentally studied, with emphasis on several key points such as the effect of dopant-dopant interactions on dopant diffusion mechanisms and in the electrical activation.

The purpose of this work is first to investigate the RTA-induced redistribution of implanted As and $\mathrm{B}$ in polysilicon/monocrystalline silicon emitter structures dedicated to BiCMOS crrcuits. Secondary Ion Mass Spectroscopy is used for dopant profiling, whereas sheet resistance measurements are performed in order to point out the electrical activation of the dopants as a function of the annealing parameters. Moreover, with Hall effect measurements, we have access to the carrier density into such a structure.

The experimental procedure for test wafer fabrication are presented in Section 2 together with the characteristics of the RTA machine and the details of the characterization of annealed structures. Experimental SIMS profiles, results of sheet resistance and Hall measurements are commented upon Section 3. We discuss the results of this work in Section 4, with emphasis on the effects of As and B co-implantation on the redistribution of B, and on the electrical activation.

\section{Experiment}

In this work, we deal with unpatterned test wafers realized according to the fabrication sequence used for BiCMOS devices at the CNET/CNS (see the schematic cross-section of the bipolar transistor in Fig. 1). The base material is (100) Czochralski-grown 4-in.-diameter wafers of $0.5 \Omega \mathrm{cm}$ Phosphorus-doped silicon. P-type $8-15 \Omega \mathrm{cm}$ Boron-doped silicon wafers are also used for sheet resistance measurement of the $\mathrm{N}^{+}$emitter. However, as no difference in dopant redistribution between the $\mathrm{N}$ and $\mathrm{P}$ substrate is observed, no further reference to the substrate type will be made hereafter. Prior to polysilicon deposition, the gate oxide is removed by dip etch in HF, and the wafers are given a standard RCA cleaning which leaves a very thin oxide layer. This procedure is shown to be effective in preventing the epitaxial realignment of the polysilicon layer onto the monocrystallne substrate at high temperature [1], while minimizing the possible diffusion barrier effects of the interface. After RCA cleanıng, a $380 \mathrm{~nm}$ thick polysilicon layer is deposited at $620^{\circ} \mathrm{C}$ from $\mathrm{SiH}_{4}$ decomposition in a LPCVD reactor with a residual pressure of $600 \mathrm{mT}$. Afterwards, the implantation of As is performed at $100 \mathrm{keV}$ with a dose of $10^{16} \mathrm{~cm}^{-2}$, and is followed by the B implantation at $30 \mathrm{keV}$ with a dose of $2 \times 10^{15} \mathrm{~cm}^{-2}$ for the extrinsic base doping (see Fig 1). Two additional series of wafers received 


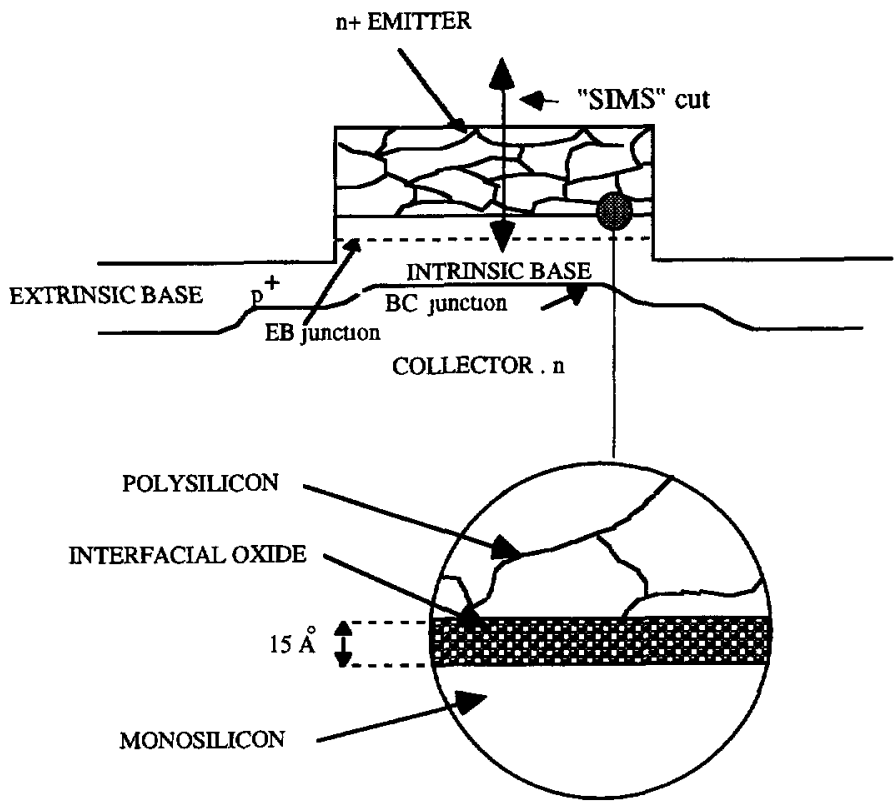

Fig. 1. - Schematic section of a bipolar polysilicon emitter structure for B1CMOS devices.

only a single implant, either As or B, in order to compare the diffusion of one single dopant with the co-diffusion of the two dopants in the bilayer.

The annealings are performed in a $30 \mathrm{~kW}$ ADDAX R1000 machine of AET under Ar atmosphere. A description of this annealing device has been reported elsewhere [6]. The implanted wafer are cut in $1 \times 1 \mathrm{~cm}^{2}$ samples and placed on a 4 -in.-diameter Si sample holder, at the center of which a type $\mathrm{K}$ thermocouple is cemented for temperature control and measurement via a data acquisition system.

The SIMS measurements are achieved with a Cameca IMS4F instrument using $10 \mathrm{keV} \mathrm{Cs}{ }^{+}$ primary ions and a beam current of $80 \mathrm{nA}$. The primary beam is rastered over a $450 \mathrm{~mm}^{2}$ area. The sample potential is kept at $4500 \mathrm{~V}$, and the signal of ${ }^{11} \mathrm{~B},{ }^{30} \mathrm{Si}_{2}^{+}$, and ${ }^{75} \mathrm{As}^{+}$secondary ions are recorded from a $100 \mathrm{~mm}^{2}$ area at the crater center. An energy filter is used to discriminate the ${ }^{75} \mathrm{As}$ and the ${ }^{29} \mathrm{Si}^{30} \mathrm{Si}^{16} \mathrm{O}$ species. In these conditions the detection limit is about $10^{15} \mathrm{~cm}^{-3}$ for $\mathrm{B}$ and $2 \times 10^{16} \mathrm{~cm}^{-3}$ for As. The vertical axis of the concentration versus depth curves were calibrated using a standard sample for As with a $5 \times 10^{20} \mathrm{~cm}^{-3}$ maximum concentration. At high As concentration, this calibration is subjected to some errors, to be taken into account only at the concentration maximum of the as-implanted As profiles. The concentration scale of the $B$ profiles is derived by normalizing the $B$ signal to the known implant dose. The scale on the horizontal axis is obtained by measurement of the crater depths using an "alphastep" profilometer. No significant difference is noticed in the erosion rate between polysilicon and monocrystalline silicon.

On the other hand, we have been dealing with the problen of outdiffusion of dopants, which could occur at high annealing temperature. In order to study possible dopant loss on other similar processed samples during the rapid thermal annealing, $400 \mathrm{~nm}$ of boro-phospho silicate glass were also deposited by chemical vapor deposition onto the polycrystalline silicon as a capping layer. Only at $1150{ }^{\circ} \mathrm{C}$ a loss of roughly $10 \%$ of the fluence seems to be observed 
between capped and uncapped samples, which is in the range of the SIMS reproducibility in a routine analysis [7]. Then, although we have to be cautious concerning the real value of the concentration (especially for $C_{\max }$ ), flat profiles observed at the surface of the samples, at high annealing temperature, seems an indication of an absence or a weak outdiffusion.

The electrical activation of the annealed $\mathrm{N}^{+}$layers (As and $\mathrm{B}$ co-diffusion) on the P-type substrate as a function of the annealing temperature is investigated in two modes: sheet resistance and Hall effect measurements. The latter are performing using a current supply (Keitley 220) and by reversing both the current, $I$, and the magnetic field, $B(1 \mathrm{~T})$, during Hall measurements. The resistivity $\rho$ and the carrier concentration $n_{\mathrm{H}}$ are given by:

$$
\rho=\frac{\Pi f \sum_{n} V_{\imath}}{n I \ln 2} \quad n_{\mathrm{H}}=A \frac{r I B}{q V_{\mathrm{H}} t},
$$

where $V_{\mathrm{H}}$ is the Hall voltage and $n$ the number of van der Pauw configurations. Since the samples behave as quasi-degenerate semiconductors and show no asymmetric effect, both the correction coefficient $f$ and the Hall factor $r$ are taken equal to unity. The factor $A$ is the anisotropy factor. It depends on the type of semiconductor. Since the arsenic profile is roughly flat into polysilicon, its doping level being much higher than that of boron one, $A$ is taken to be unity. The thickness of the active layer, $t$, is assumed to be the same as the polysilicon layer thickness, since almost all of the dopants dwell in the polycrystalline silicon. Sheet resistance is then straightforward derived from Hall resistivity measurements $\left(R_{\text {sheet }}=\rho / t\right)$.

\section{Results}

3.1. SIMS PROfILING. - The redistribution of As and B in co-diffusion is investigated by SIMS profiling for a fixed RTA plateau duration of $20 \mathrm{~s}$, and for four values of the annealing temperature, in the range $1000{ }^{\circ} \mathrm{C}-1150{ }^{\circ} \mathrm{C}$ (Fig. 2). The in-depth redistribution of As or $\mathrm{B}$ in samples implanted with either As or B, are presented in Figures 3 and 4 respectively. As expected, the fast diffusion of arsenic within the polysilicon layer produces a constant concentration up to the interface, where an As pile-up is clearly visible. Concerning this pileup, we used also oxygen ions $\left(\mathrm{O}_{2}^{+}\right)$as the primary beam, in order to achieve a high fractional yield of dopant (secondary) ions. Oxygen is known to be more efficient (compared to cesium) for such an experiment, since the surface is almost completely oxidized to $\mathrm{SiO}_{2}$. Therefore, any oxide inclusion (e.g. at the interface between poly-Si and mono-Si) is not expected to lead to an additional enhancement of the secondary ion yield of the dopant ions. SIMS profiles realized with ${ }^{16} \mathrm{O}_{2}^{+}$as a primary on source, combined with an oxygen leak onto the sample (oxidation during sputtering), also exhibit an interface peak with the same amplitude. So, the As pileup can be considered a real phenomenon, and not an artifact due to oxide inclusions at the interface. The origin of this pile-up may be either grain-boundary segregation or trapping at the thin interfacial layer produced by the RCA cleaning, or both [1]. The amount of As segregated at the interface is not significantly affected by increasing the annealing temperature, which is an evidence that no epitaxial realignment of the polysilicon layer is produced by the RTA up to $1150{ }^{\circ} \mathrm{C}$ for a $20 \mathrm{~s}$ duration. Furthermore, if the polysilicon layer would have epitaxially aligned to the substrate either in part or completely, the slope of the dopant concentration should be continuous across the interface because of equal diffusion on both sides [8]. This point has been already confirmed by TEM measureinents which show large grains extending over the whole thickness of the polysilicon layer, after the annealings [9].

It is worthfully to try to raise a doubt about comparison of the SIMS results using as a primary beam either cesium or oxygen Ion mixing is known to be lesser with oxygen than 


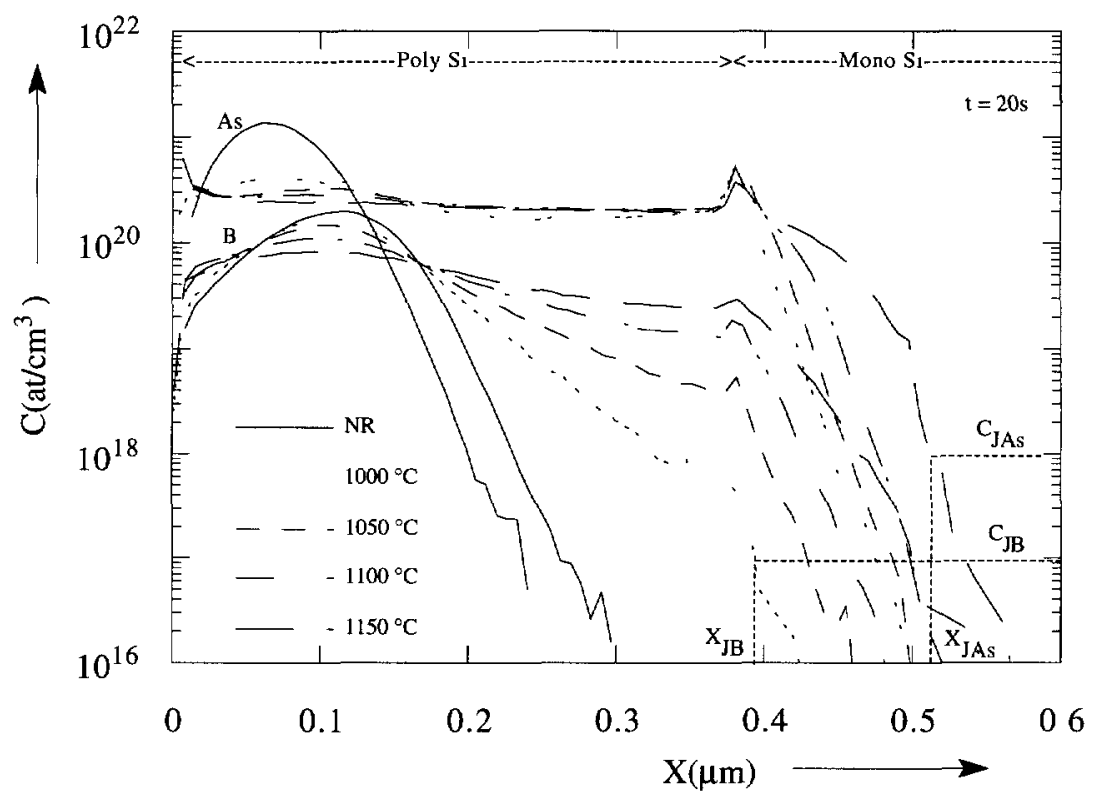

Fig. 2. - SIMS profiles of As (100 keV, $\left.10^{16} \mathrm{~cm}^{-2}\right)$ and $\mathrm{B}\left(30 \mathrm{keV}, 2 \times 10^{15} \mathrm{~cm}^{-2}\right)$ as-implanted and after a RTA for $20 \mathrm{~s}$, in a $380 \mathrm{~nm}$ thıck polysilicon LPCVD layer deposited at $620^{\circ} \mathrm{C}$ on n-type monocrystalline silicon.

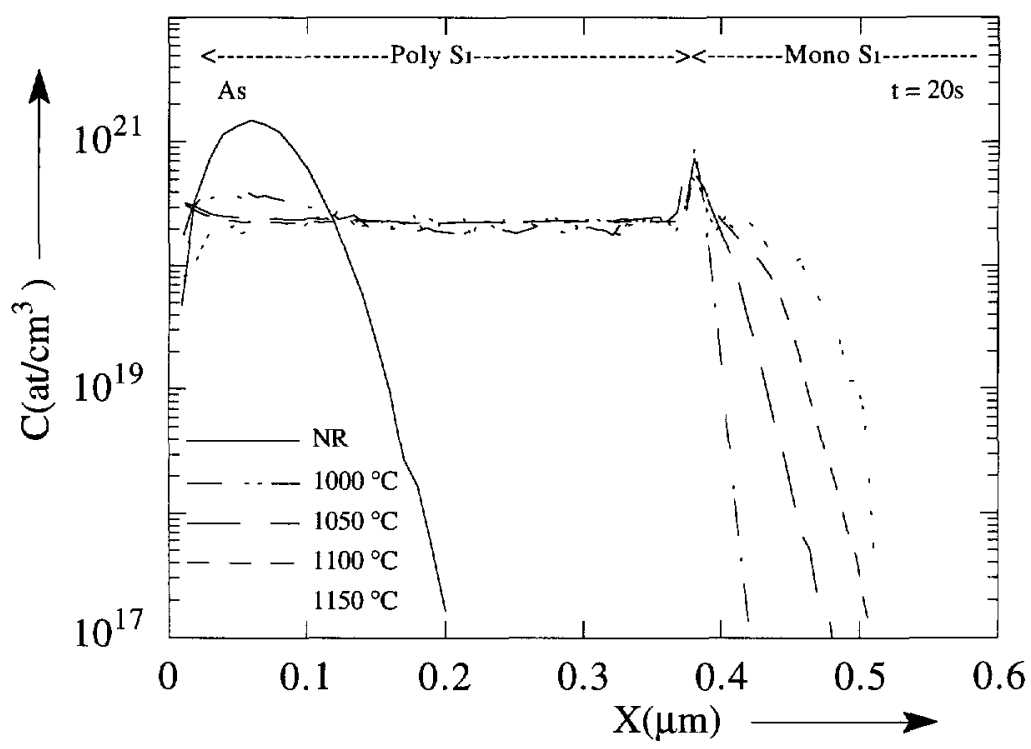

Fig. 3. - SIMS profiles of As implanted alone $\left(100 \mathrm{keV}, 10^{16} \mathrm{~cm}^{-2}\right)$, as-implanted, and after RTA for $20 \mathrm{~s}$. 


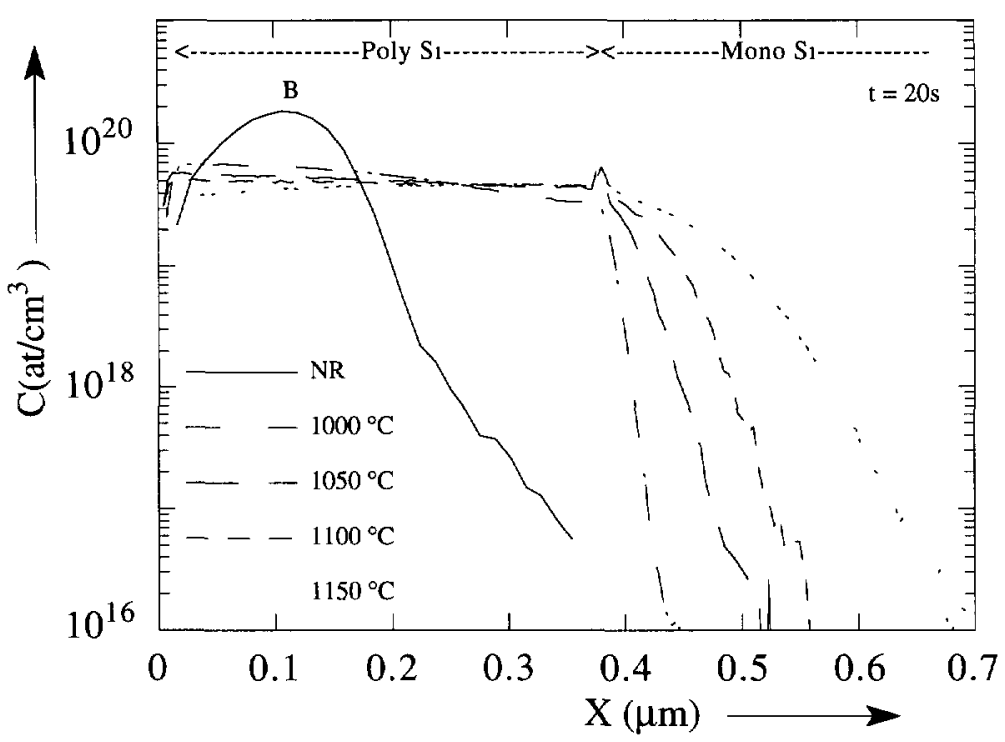

Fig. 4. - SIMS profiles of $\mathrm{B}$ implanted alone $\left(30 \mathrm{keV}, 2 \times 10^{15} \mathrm{~cm}^{-2}\right)$, as-implanted, and after RTA for $20 \mathrm{~s}$.

with cesium. Concerning the detection limit of the ionic probe, cesium is preferable for arsenic $\left(3 \times 10^{16} \mathrm{~cm}^{-3}\right.$ with $\mathrm{O}_{2}^{+}$and $5 \times 10^{14} \mathrm{~cm}^{-3}$ with $\left.\mathrm{Cs}^{+}\right)$, since it is oxygen the best one for boron $\left(5 \times 10^{13} \mathrm{~cm}^{-3}\right.$ with $\mathrm{O}_{2}^{+}$and $6-7 \times 10^{14} \mathrm{~cm}^{-3}$ with $\left.\mathrm{Cs}^{+}\right)$. Then, we did both the experiments, i.e we used alteratively $\mathrm{O}_{2}^{+}$and $\mathrm{Cs}^{+}$for arsenic and boron. No significant differences appeared in the SIMS profiles (up to the detection limits). Codiffusion, with arsenic in the higher dose, being the key point in our study with respect to the device, we have presented only SIMS profiles using cesium as primary beam.

Moreover, a steep decrease in the As profiles is observed in the monocrystalline substrate, with a concentration enhanced diffusion region in the vicinity of the interface, and a slower diffusion region below. The penetration of the As into the underlying monocrystal substrate increases slightly with the annealing temperature. The $1100^{\circ} \mathrm{C}$ anneal, for instance, produced a less than $100 \mathrm{~nm}$ thick $\mathrm{N}^{+}$layer in the monocrystalline substrate. The high As concentration at the interface is thought to be electrically active in the monocrystalline side, since it is less than the saturation value reported for As at $1100{ }^{\circ} \mathrm{C}\left(4 \times 10^{20} \mathrm{~cm}^{-3}\right)$ [10]. Note that the extrapolations of the As profiles in monocrystalline silicon and in polysilicon up to the interface give the same concentration $\left(3 \times 10^{20} \mathrm{~cm}^{-3}\right.$ at $\left.1100^{\circ} \mathrm{C}\right)$. This is an indication that no diffusion barrier exists at the interface as already reported [1]. Concerning this absence of barrier, the oxide breaking is not a sine qua non condition, certainly because of its thinness [8] (although it is generally convenient for making the diffusion easy). In our previous work, T.E.M measurements have shown that oxide balls up only for annealing temperature up to $1100^{\circ} \mathrm{C}$ [9]. The oxide quality depends not only on its thickness, but also on cleaning process of the silicon wafer. on the process conditions of the deposition of the polysilicon and on the types of dopants.

As we can observe, arsenic profiles and, to a lesser extent, boron profiles in polysilicon are roughly flat at these temperatures. The dopant profiles in co-diffused samples are different in several respects from those obtained for the single implants. First, no exponential tail is present in the as-implanted B profile in co-diffused samples. This is a consequence of the amorphization 


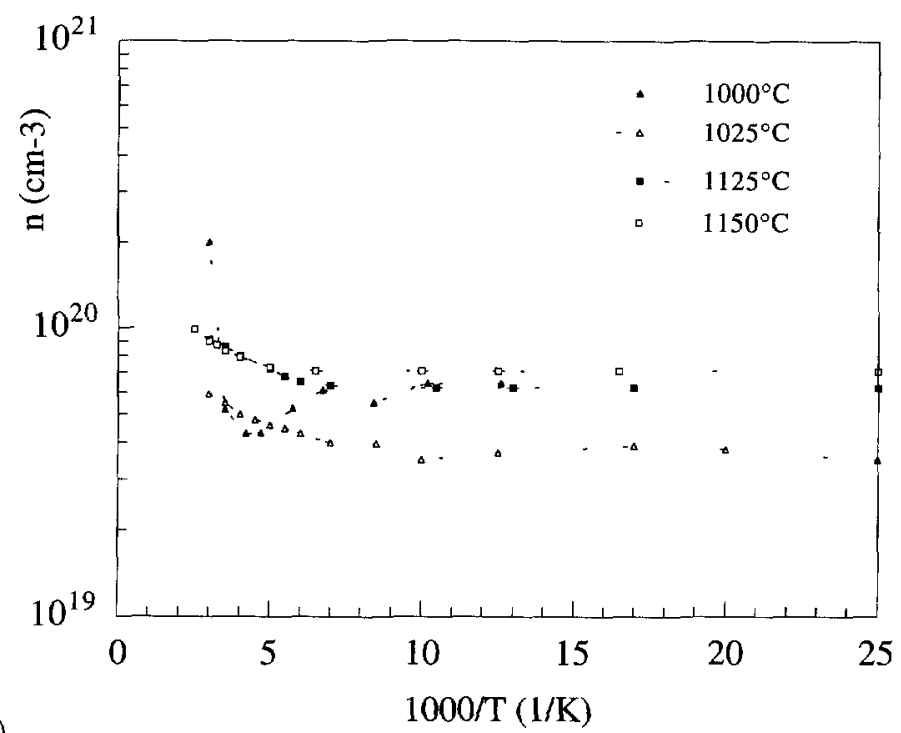

a)

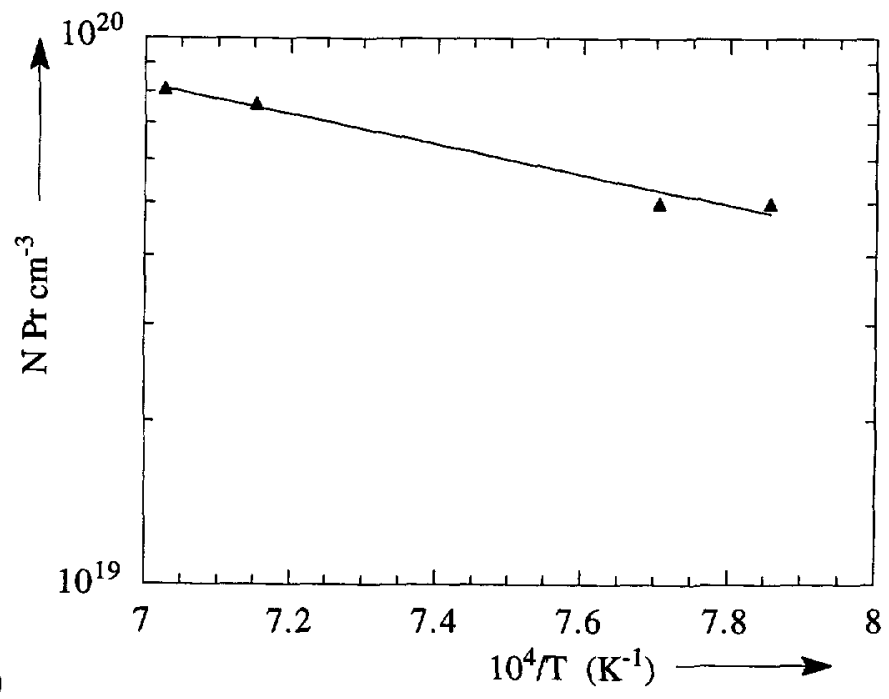

Fig. 5. - a) Hall measurements in As $\left(100 \mathrm{keV}, 10^{16} \mathrm{~cm}^{-2}\right)$ and $\mathrm{B}\left(30 \mathrm{keV}, 2 \times 10^{15} \mathrm{~cm}^{-2}\right)$ - Implanted films: carrier density versus measurement temperature b) Hall measurements in As and B-implanted films at room temperature: carrier density versus RTA temperature.

of the polysilicon top layer by the high dose As implantation. Secondly, the diffusion of B is retarded in the presence of $\mathrm{As}$, as clearly shown by the decreasing $\mathrm{B}$ concentration within the polysilicon layer towards the interface, and the remainder of the implantation peak in the diffused profile. The diffusion of As is also affected by the presence of $B$, but to a lesser extent, and the retardation is only visible in the region of maximum of $B$ concentration in the polysilicon layer. The consequence of these retardation effects is a shallower penetration of the dopants into the monocrystalline substrate, especially $\mathrm{B}$, with a profile tail that does not extend beyond that of As. This feature of the As and B co-diffusion is beneficial for the formation of a shallow $\mathrm{N}^{+}$emitter without increasing the base doping level. 


\subsection{Hall Measurements}

Carrier Density. - At low measurement temperature (see Figs. 5a, b), the curves show the degeneracy ( $N_{\text {HALL }}$ is constant), around the $10^{20} \mathrm{~cm}^{-3}$ range. For an RTA temperature of $1000^{\circ} \mathrm{C}$, we can observe a minimum versus the measurement temperature; this one could be induced by electrical non-homogeneity at such a weak RTA temperature. Since this minimum disappears at $1025^{\circ} \mathrm{C}$, we can conclude that some essential defects are relieved.

For RTAs of $1125^{\circ} \mathrm{C}$ and $1150^{\circ} \mathrm{C}$, the curves are roughly superimposed and flat; that is a criterion which indicates we are near from the full electrical activation of the structures.

On an other hand, we can remark that the logarithm of the ionisation rate of arsenic dopants is varying, in inverse ratio to RTA temperature, into the the range $25 \%\left(1000{ }^{\circ} \mathrm{C}\right)-40 \%$ $\left(1150^{\circ} \mathrm{C}\right)$, at room measurement temperature. Arsenic which is segregated at grain boundaries is generally inactive. The active arsenic profile is considerably different than the total arsenic profile. Some authors [11], using Hall profiling, do indicate that only $20 \%$ of the arsenic is electrically active, the remainder being segregated at the grain boundaries.

Hall Mobility. - The Hall mobility increases versus the RTA temperature (see Figs. 6a, b); this is due to the well-known mixed effect of grain growth and disorder reduction. We observe its saturation at high RTA temperature because of grain growth saturation; the small increase of mobility between the RTA temperature of $1125^{\circ} \mathrm{C}$ and $1150{ }^{\circ} \mathrm{C}$ could be interpreted by the activation of the arsenic dopant (the mobility increases with the carrier concentration in polysilicon, at the contrary of monocrystalline silicon).

Resistıvity and Sheet Resistance. - As mentioned above, we have extracted the sheet resistance $\left(R_{\text {sheet }}=\rho / t\right.$, Fig. $\left.7 \mathrm{~b}\right)$ versus the annealing temperature from the measured resistivity $\rho$ (Fig. 7a). A very good agreement is obtained with the direct four-point probe measurements (Fig. 7b)

The sheet resistance decreased strongly with the annealing temperature, up to $1100{ }^{\circ} \mathrm{C}$, according to the increasing electrical activation of As atoms. A saturation of the RTA-induced activation process is observed above $1150^{\circ} \mathrm{C}$, with a sheet resistance of about $60 \Omega$.

\section{Discussion}

Retarded diffusion of $\mathrm{B}$ in the presence of a background concentration of As dopants in poly-Si, is the most significant feature to be emphasized; the amorphization by As atoms cannot slow down dramatıcally the diffusion because of the fast recrystallization, at the first beginning of the annealing. This phenomenon cannot be essentially attributed to an electric field effect, from arsenic over boron, since arsenic is always deeper than boron from the implantation stage up to the end of the annealing. Indeed, for same process parameters, but considering only a monocrystalline silicon wafer (no polysilicon), we have already observed that boron diffuses more rapidly indepth, than arsenic [12]; moreover, within this latter framework, coimplantation-induced electric field has been implemented in Fick-type models, which gave numerical simulations similar to SIMS measurements. What more is, ion pairing between two different species (As,B), i.e. dopant-dopant interactions, that can further lower the mobile fraction of $B$ atoms, does not seem crucial at such high annealing temperatures [13] In the first seconds of the RTA plateau, the highly mobile As atoms diffuse beyond the B implantation tail and thus can reach the interface rapidly; a fraction of the $B$ atoms, into the grauns, are perhaps being paired with electrically active As atoms in the maximum $B$ concentration region; but, if we assume an important pairing between these two species, As should be slow down as 


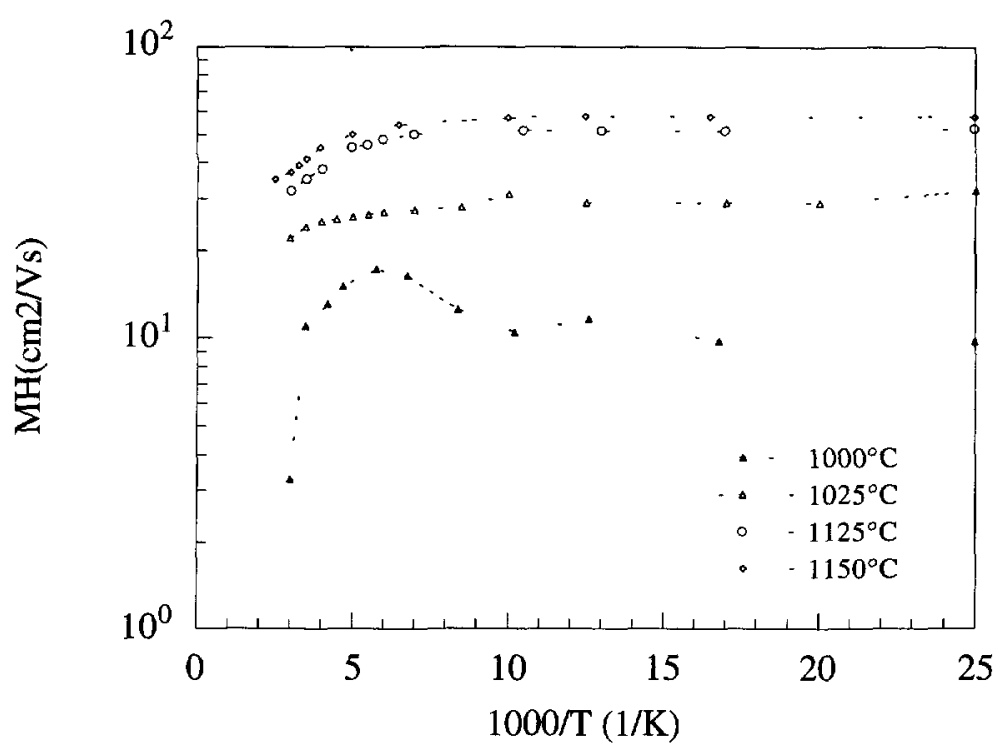

a)

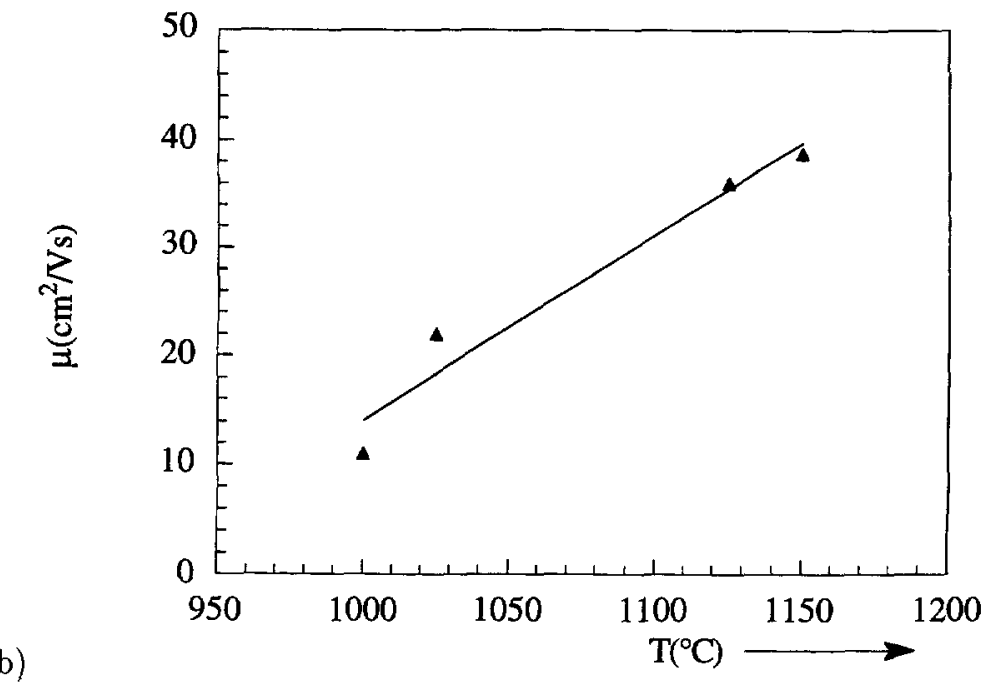

Fig. 6. - a) Hall measurements in $A s\left(100 \mathrm{keV}, 10^{16} \mathrm{~cm}^{-2}\right)$ and $\mathrm{B}\left(30 \mathrm{keV}, 2 \times 10^{15} \mathrm{~cm}^{-2}\right)$-implanted films. mobility versus measurement temperature. b) Hall measurements in As and B-implanted films at room temperature: mobility versus RTA temperature.

well. So, we think that the key hypothesis lays in the fact that these B atoms can not go easily into or along the grain boundaries, because of the presence of As atoms which are well known to segregate at grain boundaries.

This work gives an experimental insight into the physical mechanisms involved in the formation of the shallow $\mathrm{N}^{+}$emitters of bipolar transistors for the BiCMOS technology, that uses a LPCVD polysilicon layer co-implanted with As and B, further subjected to a RTA. The diffusion retardation effect of the co-implantation is strong for $\mathrm{B}$, and this feature is beneficial for 

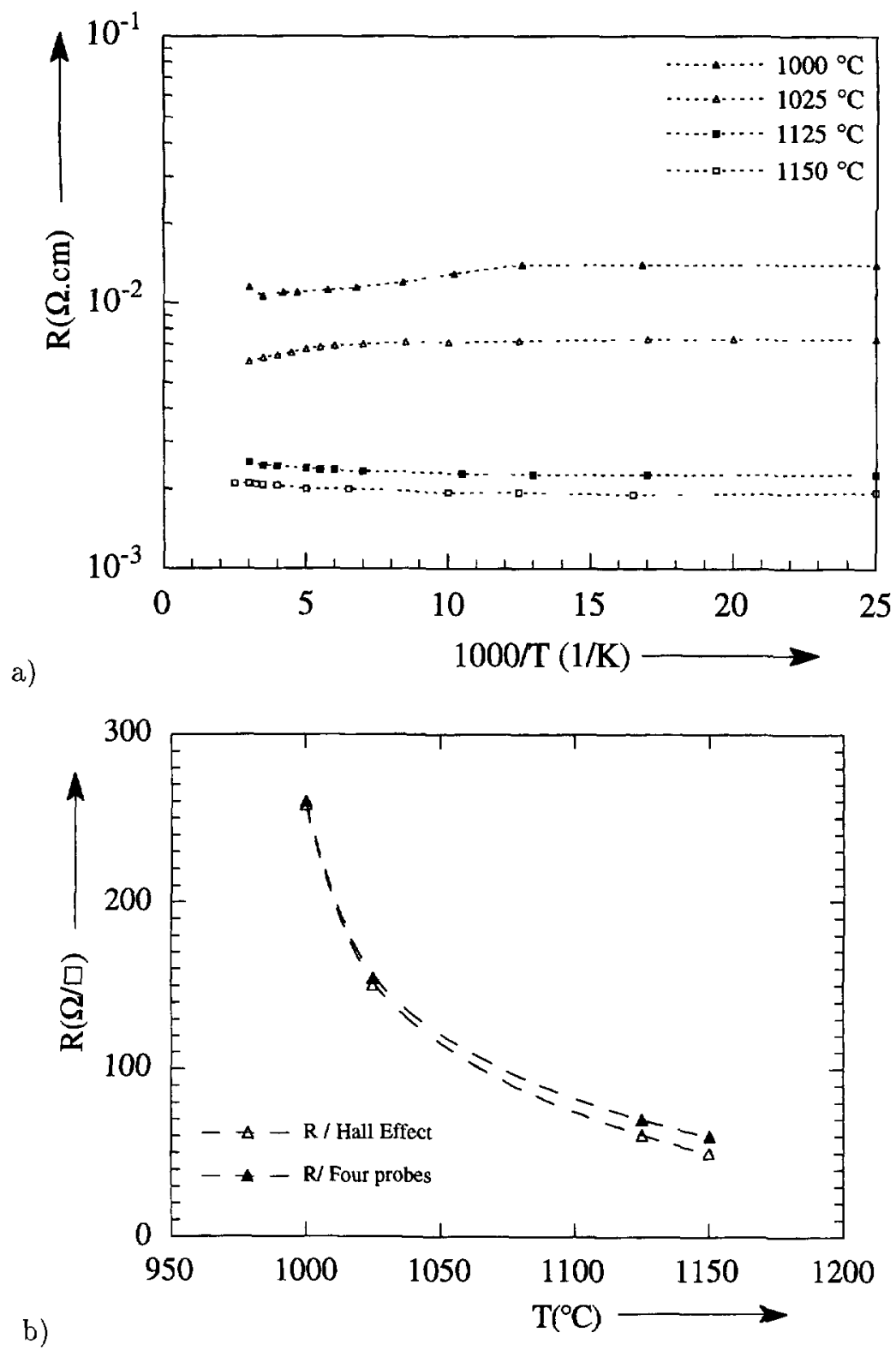

Fig. 7. - a) Hall measurements in As $\left(100 \mathrm{keV}, 10^{16} \mathrm{~cm}^{-2}\right)$ and $\mathrm{B}\left(30 \mathrm{keV}, 2 \times 10^{15} \mathrm{~cm}^{-2}\right)$-implanted films. resistivity versus measurement temperature. b) Hall measurements versus RTA temperature in the As and B-implanted films, measured at room temperature: sheet resistance. $(\triangle)$, four probe measurements: (A).

the $\mathrm{N}^{+}$doping profile in the monocrystalline emitter region and for the integrity of the intrinsic base region. The penetration of As atoms in the monocrystalline substrate is only slightly affected by the co-diffusion, so that a highly doped and steep emitter profile is obtained 


\section{Conclusion}

We have presented in this paper experimental results on codiffusion of arsenic and boron in polysilicon/monocrystalline silicon layers during RTA in the temperature relevant to the fabrication of bipolar transistor compatible with CMOS technologies. A remarkable observation is that during the annealing, boron diffuses faster alone than in codiffusion when it is in the lowest dose in a NPN configuration, into polysilicon. More than an electric field effect or dopant-dopant interactions, we assume that the dopant in the highest dose could saturate grain boundary traps and then slows down the diffusion of the other dopant of opposite sign. Moreover, with direct sheet resistance four-point probe measurements and Hall effect experiments, we get the electrical activity of these structure, as well as the carrier density, versus the annealing temperature.

\section{Acknowledgments}

This work has been performed under contract with the CNET. The authors wish to thank the staff of the CNET/CNS/APF pilot line for the wafer preparation.

\section{References}

[1] Schaber H., Criegern R. and Weitzel I., Analysis of polycrystalline silicon diffusion sources by secondary ion mass spectrometry, J. Appl. Phys. 58 ( 1985) 4036-4042.

[2] Böhm H.J., Wendt H., Oppolzer H., Masseli K. and Kassing R., Diffusion of B and As from polycrystalline silicon during rapid optical annealing, Appl. Phys. 62 (1987) 2784-2788.

[3] Giroult G., Nouailhat A and Gauneau M, Study of a WSi 2 /polycrystalline silicon/monocrystalline silicon structure for a complementary metal-oxide-semiconductor for a compatible self-aligned bipolar transistor emitter, J. Appl. Phys. 67 (1990) 515-523.

[4] Horiuchi S. and Blanchard R., Boron diffusion in polycrystalline silicon layers, Solid-State Electronics 18 (1975) 529-532.

[5] Swaminathan B., Saraswat K.C. and Dutton R.W., Diffusion of arsenic in polycrystalline silicon, Appl. Phys. Lett. 40 (1982) 795-798

[6] Chaussemy G., Canut B., Kumar S.N., Barbier D. and Laugier A., Arsenic Redistribution and Outdiffusion in implanted Czochralski-grown p-type silicon during rapid thermal annealing. in "Fundamental of Beam-Solid Interactions and Transient Thermal Processing", M.J. Aziz, L.E. Rehn and B Stritzker, Eds., Mat. Res. Soc. Proc. Vol. 100, MRS (Pittsburgh, 1988) pp. 695-699.

[7] Lux G.. Reproductibility of the Quantitative SIMS Analysis of Ion-Implanted Si Wafers, Internal Report (Charles Evans and Associates, 301 Cheapeake Drive, Redwood City, CA 94063, USA, 1990).

[8] Josquin W.J.M.J., Boudewijn P.R. and Tamninga Y., Effectiveness of polycrystalline silicon diffusion sources, Appl. Phys. Lett. 43 (1983) 960-962.

[9] Gontrand C., Merabet A., Krieger-Kaddour S., Dubois C. and Vallard J.P., Analysis of rapid thermal annealings of Boron and Arsenic in polysilicon Emitter Structures, J. Elect. Mat. 22 (1993) 135-141. 
[10] Guerrero E., Poltz H.. Tielert R., Grassenbauer M. and Stingeder G., Junction Formation and Poly-si Doping for Scaled Sub-Micron CMOS Technology, J. Electrochem Soc. 129 (1982) 1826.

[11] Ashburn P., Design and realization of bipolar transistors (Chichester Wiley \& Sons, 1989) p. 198.

[12] Gontrand C., Ancey P., Haddab Y. and Chaussemy G., Diffusion and codiffusion of boron and arsenic into monocrystalline silicon during rapid thermal annealing, Semicond. Sci. Technol. 7 (1992) 181-187.

[13] Cowern N.E.B., Ion pairing effects on substitutional impurity diffusion in silicon, Appl. Phys. Lett. 54 (1989) 7035-7040. 